\title{
AN ANALYSIS OF THE PERFORMANCE OF DECONSTRUCTED TIRES FOR USE AS PADS IN RAILROAD TRACKS
}

\author{
Miguel SOL-SÁNCHEZ, Fernando MORENO-NAVARRO, \\ Maria Carmen RUBIO-GÁMEZ \\ Laboratorio de Ingeniería de la Construcción de la Universidad de Granada, 18071, Granada, Spain
}

Received 18 Jun 2013; accepted 29 Aug 2013

\begin{abstract}
The use of end-of-life (EOL) tires is now widespread in civil engineering work. In most cases, the tires are shredded and recycled as crumb rubber. However, this research focuses on an alternate method in which EOL tires were deconstructed to manufacture rail pads. In other words, their outer layer was removed, which made it possible to benefit from the mechanical properties of the tires without having to grind them up. The performance of the recycled tire rubber was analyzed by means of static and dynamic stiffness tests as well as by fatigue tests. The results reflected the long-term performance of the material. Also analyzed was the deterioration of its properties after various thermal and anti-ageing treatments. The results obtained were compared with those of commercial crumb rubber rail pads. The excellent performance of the rail pads made from deconstructed EOL tires shows the high potential of this material for use in railroad tracks.
\end{abstract}

Keywords: deconstructed end-of-life tires, mechanical properties, rail pads, railroad tracks.

\section{Introduction}

In the last three decades, the use of concrete sleepers in railroad tracks has become standard practice. Because the sleepers are made from concrete, they are less affected by climate factors (Federation Internationale de la Precontrainte 1987), and at the same time their strength properties make them apt for tracks subjected to heavy traffic loads. Nevertheless, since concrete sleepers are 3-5 times stiffer than wooden sleepers (Lakuši et al. 2010), it is necessary to insert an elastic pad between the rail and sleeper to reduce the stiffness of the system and thus mitigate the impact loads between the two components (Szurgott et al. 2012).

Rail pads improve the performance of railroad tracks. In fact, the traffic safety of trains depends to a great extent on the mechanical features of these elements (Sadkowski 2009). Among other technical and socio-environmental improvements, they reduce the noise and vibrations transmitted by the track when trains pass ( $\mathrm{Wu}$, Thompson 2001). The characteristic parameter of the rail pads is their stiffness value, which should be in consonance with the type of track required. For this reason, soft pads are generally used in high-speed railway tracks to dissipate the considerable amount of energy generated by train passages. In contrast, stiffer pads are better for conventional railways (Szurgott et al. 2012). For this reason, the mechanical properties of rail pads must be clearly defined so as to guarantee the smooth operation as well as the effective performance of the entire railway system.

The implementation of sustainable development policies has fostered the reuse of construction waste in civil engineering work. Many useful applications have been found for end-of-life (EOL) tires (Hernández et al. 2009; Grinys et al. 2012). In the railway sector, one of these practices consists of the use of dry asphalt rubber within sub-ballast layers (Di Mino, Di Liberto 2012). Another successful practice is the reuse of tire rubber to manufacture rail pads (Sistema MLG 2013; CDM 2013). These pads help to eliminate a kind of waste that is otherwise very difficult to dispose of, and even gives it an added value, thus contributing to sustainable development. Generally speaking, these rail pads are manufactured by grinding up the tire (separating textile and metallic components) and subsequently mixing the rubber particles with a resin binding agent. Disadvantages of this process include the cost of treating the rubber as well as the loss of mechanical properties from shredding the tires and grinding the rubber.

This research is a significant step forward in the recycling of EOL tires (Gomavial Solutions 2013) because it shows how each of the tire layers can be recovered

Corresponding author: Fernando Moreno-Navarro

E-mail:fmoreno@ugr.es 
without the need to grind up the rubber into particles. This means that the properties of the rubber remain intact, and at the same time, it is possible to benefit from all of the positive hi-tech qualities of the tire material, such as tensile strength, thermostable properties, resilience to climate impacts, etc.

This research studied and tested the viability of using the outer layer of EOL tires to manufacture rail pads. For this purpose, the static stiffness (at different load levels), dynamic stiffness, and fatigue strength of rail pads manufactured with the outer layer of deconstructed tires have been evaluated. The results were then compared with those obtained for commercial rail pads composed of crumb rubber and resin, which was used as the reference value. The effect of the climate conditions on the mechanical performance was also analyzed for both types of rail pad in order to assess their fatigue strength since this is one of the main failure modes of such pads (Ito, Nagai 2008). Moreover, further research to study rail pad dynamic response by ultrasonic method could be of interest, as other researchers have done to evaluate the performance of other construction materials (Norambuena et al 2010).

\section{Materials}

The material studied was a set of elastic rail pads made from the outer layer of EOL tires. These materials were obtained from the deconstruction of the different tire layers (outer, middle and inner), without grinding up the wastes. Figure 1a shows the visual appearance of the tire layers. After that process, the outer tire layer (tread layer) was cut into diverse pads with dimensions $(180 \pm 1 \mathrm{~mm} \times$ $140 \pm 1 \mathrm{~mm}$ ) apt for UIC 54 rails. These dimensions were also established for a set of commercial rail pads composed of crumb-rubber particles (from shredded tires) and synthetic resin used as a binding agent. Both types of rail pad had the same thickness $(4.5 \mathrm{~mm})$ to prevent this parameter from affecting the mechanical response of the pads to the loads simulating train passage. Figure $1 \mathrm{~b}$ shows the rail pads tested in this study.

Table 1 lists the mechanical characteristics of the two types of material (deconstructed tires (DT) and crumb rubber (CR) with a resin binder), which were used to manufacture the rail pads in this study.

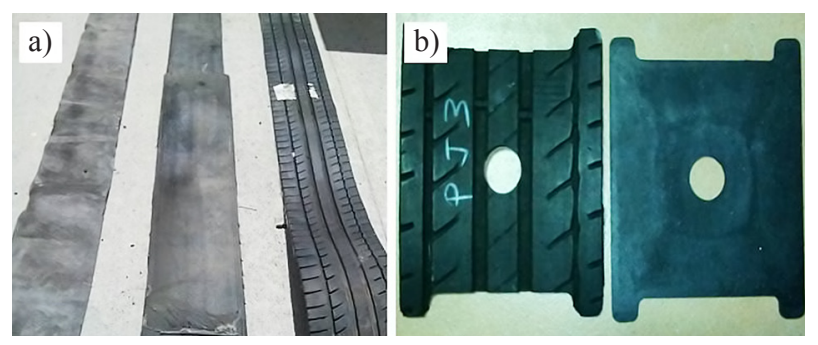

Fig. 1. a) Tire layers: inner (left), middle (center) and outer (right). b) Rail pad made of deconstructed EOL-tires (left); commercial rail pad made of crumb rubber particles (right)
Table 1. Mechanical properties of deconstructed tire (DT) rail pads and commercial crumb rubber $(\mathrm{CR})$ rail pads

\begin{tabular}{lcc}
\hline \multicolumn{1}{c}{ Property } & CR rail pad & DT rail pad \\
\hline $\begin{array}{c}\text { Hardness, Shore A, } \\
\text { ISO 48 (IRHD) }\end{array}$ & $66-76$ & $64-77$ \\
\hline $\begin{array}{l}\text { Minimum tensile strength, } \\
\text { ISO 37 }(\mathrm{MPa})\end{array}$ & 3.0 & 9.5 \\
\hline $\begin{array}{l}\text { Minimum tensile strength, } \\
\begin{array}{l}\text { ISO 37 }(\mathrm{MPa}), \text { after 7 } \\
\text { days at } 70^{\circ} \mathrm{C}\end{array}\end{array}$ & 3.0 & 8.8 \\
\hline
\end{tabular}

\section{Experimental set-up}

In order to ascertain the mechanical performance of the materials, it was first necessary to determine the static secant stiffness (UNE-EN 13146-9:2011) and dynamic secant stiffness (UNE-EN 13481-2 Annex B:2003) of the CR rail pads as well as for the DT rail pads. Similarly, with a view to assessing the durability and long-term dynamic performance of both materials, their fatigue strength was evaluated by applying the Locati method for fatigue testing (Locati 1952), a method used by other researchers for this purpose (Carrascal et al. 2007).

The static response of the rail pads was assessed at two different load levels: (i) $20-95 \mathrm{kN}$; (ii) $100-200$ $\mathrm{kN}$. The objective was to analyze the response of the rail pads to the different loading conditions that railroad tracks are subjected to. The vertical secant stiffness under loads of 20-95 kN (UNE-EN 13146-9:2011) reflects the mechanical performance of the rail pads, namely, their capacity to damp vibrations and protect the ballast for a load level corresponding to that of high-speed train lines. In addition, the secant stiffness for loads of $100-200 \mathrm{kN}$ (UNE-EN 13146-9:2011) indicates the protection that the rail pad provides for the sleeper and ballast in the case of exceptionally heavy loads, due to defects in the rail, wheel, or the sleeper soling in the ballast.

In both static tests, the elastic elements were subjected to 3 loading cycles ranging from a minimum load of $0.5 \mathrm{kN}$ to a maximum load of $95 \mathrm{kN}$ for a stiffness of $20-95 \mathrm{kN}$ and to a maximum load of $200 \mathrm{kN}$ for higher stiffness values. The loading speed was $15 \mathrm{kN} / \mathrm{min}$ for the first two cycles and $5 \mathrm{kN} / \mathrm{min}$ for the third cycle. The unloading speed was $50 \mathrm{kN} / \mathrm{min}$. In each cycle, the maximum load was applied for one minute and the minimum load for five minutes.

These static tests were used to calculate the values of the vertical secant stiffness $(K)$ of the rail pads, obtained from the Eqn (1). Furthermore, for the third loading cycle, the vertical displacements measured at the four corners of the rail pads were recorded. Figure 2 shows an example of the load-displacement curves measured in the last loading cycle of the secant stiffness test.

$$
K=\frac{F_{\max }-F_{\min }}{d_{\max }-d_{\min }}\left(\frac{\mathrm{kN}}{\mathrm{mm}}\right),
$$




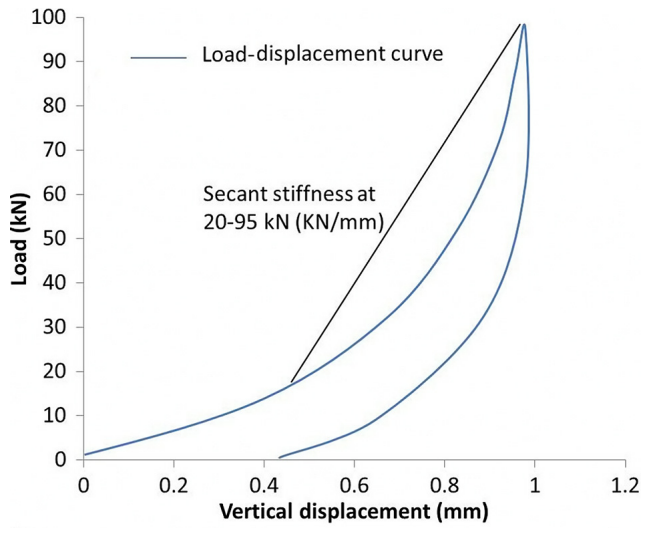

Fig. 2. Load-displacement curve, as recorded in the $20-95 \mathrm{kN}$ static test

where: $F_{\max }$ corresponded to $95 \mathrm{kN}$ and $F_{\min }$ to $20 \mathrm{kN}$ for the $20-95 \mathrm{kN}$ test, whereas $F_{\max }$ was equal to 200 $\mathrm{kN}$ and $F_{\min }$ to $100 \mathrm{kN}$ for the $100-200 \mathrm{kN}$ test. Besides, $d_{\max }$ and $d_{\min }$ corresponded to the mean displacements measured for the force values applied during the third loading cycle in each static test.

This study also evaluated the dynamic performance (UNE-EN 13481-2 Annex B:2003) of the rail pads since this is a basic factor to predict the response of the railroad track to rolling trains. Accordingly, 1000 loading cycles of 20-95 kN were applied at a frequency of $4 \mathrm{~Hz}$ (according to UNE-EN 13481-2 Annex B:2003), which simulated the repeated loads produced by trains. In each loading cycle, the vertical displacements at the 4 corners of the rail pads were evaluated. This made it possible to assess the evolution of the dynamic stiffness and energy dissipated by these materials.

To complete the analysis of the mechanical performance of the rail pads, the durability and long-term dynamic response with the Locati method for accelerated fatigue testing was studied (Locati 1952). This procedure was used since in other research (Carrascal et al. 2007), the Locati test produced results that were similar to those obtained with the conventional fatigue test. Accordingly, four load levels $(20 / 75,20 / 90,20 / 105$, and 20/120 kN) of 50,000 cycles each were applied at a frequency of 4 $\mathrm{Hz}$. In each cycle, the vertical displacement of the rail pad corners was measured to analyze the evolution of the dynamic stiffness and dissipated energy. Furthermore, before and after the fatigue test, a static test was performed on the rail pads to see whether their mechanical properties had been affected.

After ascertaining the mechanical properties of both types of rail pad, the resistance of these materials to environmental factors was then evaluated since climate deterioration is the principal failure mode for rail pads (Ito, Nagai 2008). Accordingly, an elastic pad made of each type of material was subjected to a freeze-thaw process, whereas another pad was subjected to a thermal ageing process. To assess resistance to low temperatures, the pads underwent 50 freeze-thaw cycles. The samples were thus maintained at $-20^{\circ}$ for three hours and then immersed in water at $12^{\circ}$ for another 3 hours. For the thermal ageing test, the pads were stored for 7 days at $70^{\circ}$.

These artificial deterioration processes were performed in accordance with ADIF regulations (ADIF 2013) for the evaluation of the resistance of these elastic materials to climate factors. The change in the static and dynamic performance of both types of rail pad was thus studied at $4 \mathrm{~Hz}$ for loads of $20-95 \mathrm{kN}$.

\section{Results and discussion}

\subsection{Static stiffness}

Table 2 lists the values of vertical secant stiffness at loads of $20-95 \mathrm{kN}$ and $100-200 \mathrm{kN}$ for the samples. As an indication of the homogeneity of the materials, the mean values and variation coefficients are showed.

Table 2. Results obtained in the static tests for DT and CR rail pads.

\begin{tabular}{|c|c|c|c|c|}
\hline \multicolumn{2}{|c|}{ Rail pads } & $\begin{array}{c}\text { Secant } \\
\text { Stiffness } \\
(\mathrm{kN} / \mathrm{mm})\end{array}$ & $\begin{array}{l}\text { Mean value } \\
(\mathrm{kN} / \mathrm{mm})\end{array}$ & $\begin{array}{c}\text { Variation } \\
\text { coefficient } \\
(\%)\end{array}$ \\
\hline \multicolumn{5}{|c|}{$20-95 \mathrm{kN}$ test } \\
\hline \multirow{3}{*}{$\begin{array}{l}\mathrm{CR} \text { rail } \\
\text { pads }\end{array}$} & Sample 1 & 287.86 & \multirow{3}{*}{278.51} & \multirow{3}{*}{5.55} \\
\hline & Sample 2 & 266.02 & & \\
\hline & Sample 3 & 281.64 & & \\
\hline \multirow{3}{*}{$\begin{array}{l}\text { DT rail } \\
\text { pads }\end{array}$} & Sample 1 & 290.84 & \multirow{3}{*}{268.80} & \multirow{3}{*}{8.16} \\
\hline & Sample 2 & 246.95 & & \\
\hline & Sample 3 & 268.62 & & \\
\hline \multicolumn{5}{|c|}{$100-200 \mathrm{kN}$ test } \\
\hline \multirow{3}{*}{$\begin{array}{l}\text { CR rail } \\
\text { pads }\end{array}$} & Sample 1 & 352.61 & \multirow{3}{*}{446.97} & \multirow{3}{*}{27.13} \\
\hline & Sample 2 & 583.77 & & \\
\hline & Sample 3 & 404.53 & & \\
\hline \multirow{3}{*}{$\begin{array}{l}\text { DT rail } \\
\text { pads }\end{array}$} & Sample 1 & 855.43 & \multirow{3}{*}{726.05} & \multirow{3}{*}{15.95} \\
\hline & Sample 2 & 690.60 & & \\
\hline & Sample 3 & 632.11 & & \\
\hline
\end{tabular}

In regards to the deconstructed tire (DT) rail pads (Gomavial Solutions 2013), the static stiffness for loads of $20-95 \mathrm{kN}$ was similar to the value recorded for commercial crumb rubber (CR) rail pads. Moreover, for both types of rail pad, the stiffness variation coefficient was low $(<10.00 \%)$. Regarding the stiffness values for heavier loads $(100-200 \mathrm{kN})$, the DT rail pads were found to have lower flexibility values. This indicates that they have a lower capacity to damp the loads generated by the wheel/rail impact. Nonetheless, this is less important because of the infrequent occurrence of severe impact loads (Kaewunruen, Remennikov 2008). Furthermore, as can be observed, the results of the DT rail pads are more homogeneous than those of the $\mathrm{CR}$ rail pads which can provide a more uniform performance.

With a view to assessing the performance of the rail pads during the loading cycles of the static tests, Figure 3 
shows the load-displacement curves, measured in the last loading cycles of the secant stiffness tests $(20-95 \mathrm{kN}$ and 100-200 kN) for sample 1 of the DT and CR rail pads. These samples were selected because they had similar static stiffness values, which made them easier to compare. As can be observed in Figure 3, in the stiffness test for loads of $20-95 \mathrm{kN}$, the DT rail pad showed a greater vertical deformation than that recorded for CR rail pads. This indicates that the DT rail pad has a greater capacity to damp the loads produced by rolling trains. This reflects its viability and aptness as an elastic element in railroad tracks.

Moreover, when the loads were increased (100-200 kN stiffness test), the differences in the vertical deformation of the DT and CR pads decreased until reaching very similar values. Consequently, for compression loads approaching $200 \mathrm{kN}$, the performance of both materials was very similar. This was mainly due to the reduction in vertical displacement of the DT rail pad because of the stiffness of this material when the load levels increased during the three loading cycles in the static test.

In regards to the load-displacement curves of the rail pads in the static tests (Fig. 3), an increase in loads produced a corresponding increase in the stiffness of the DT rail pads. This behavior is in consonance with other researches (Van Krevelen 1990; Folta 2011) that also studied the behavior of rubber subjected to compression loads.

In contrast, the $\mathrm{CR}$ rail pads had a more linear deformation as the loads increased, which is possibly due to the resin binding agent. This can also be observed in Figure 4, which shows the time-displacement curves, evaluated in the last loading cycle of the $20-95 \mathrm{kN}$ static secant stiffness test. As can be observed, the most significant deformation of the DT rail pad occurred at the beginning of the loading cycle. It was also found to have a greater elastic recovery $(53 \%$ of the maximum deformation) than the commercial CR rail pad (17\%). Both types of pad showed a similar residual deformation (approximately $0.28 \mathrm{~mm}$ ). This indicates that DT rail pads have a greater elastic deformation capacity, which guarantees an effective damping of loads and vibrations produced by the passage of trains on railroad tracks.

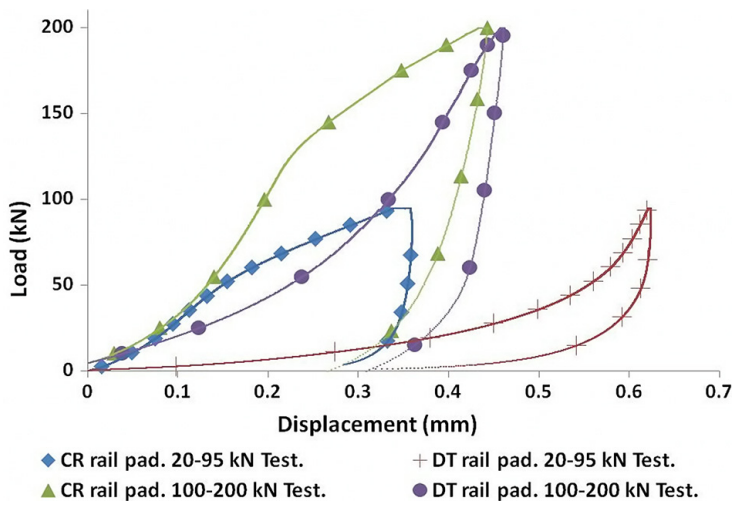

Fig. 3. Load-displacement curves obtained in the static tests

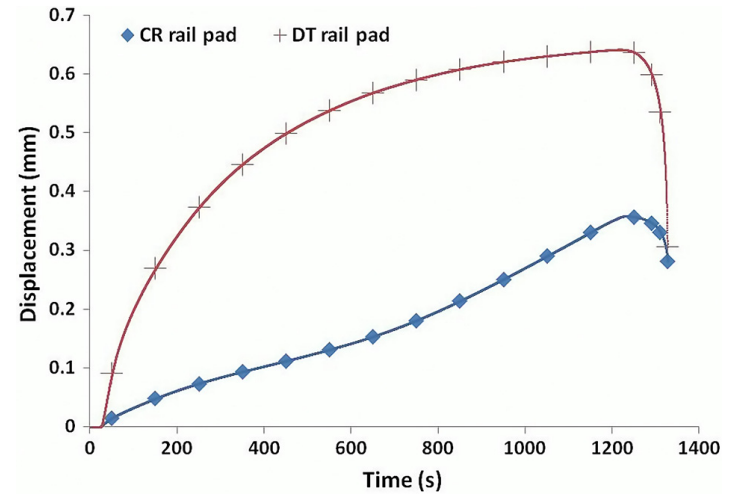

Fig. 4. Time-displacement curves measured in the static test at loads of $20-95 \mathrm{kN}$

\subsection{Dynamic stiffness}

Table 3 lists the dynamic stiffness values $(\mathrm{kN} / \mathrm{mm})$ recorded for three rail pads made from each type of material. As previously mentioned, the objective was to study the viability of using DT rail pads on railroad tracks. As reflected in the results, these rail pads were found to have lower dynamic stiffness values than CR rail pads, which means that they are able to more effectively damp vibrations and dynamic loads caused by the passage of trains (Fonseca Teixeira 2003; López Pita 2006). This also makes them more suitable for high-speed railways since this type of railroad track requires flexible rail pads that reduce excessive stiffness (Szurgott et al. 2012), and at the same time are able to dissipate part of the dynamic overloads caused by trains operating at speeds higher than $200 \mathrm{~km} / \mathrm{h}$ (Prud'Homme 1977). Furthermore, the variation coefficient of DT rail pads was very similar to that obtained for commercial CR rail pads. Once again, it was found that DT rail pads provide good results when used in railroad tracks. They are also a very effective and economical solution for the disposal of this type of waste and thus produce a wide range of socio-environmental benefits.

Table 3. Results obtained in the dynamic test for CR rail pads and DT rail pads

\begin{tabular}{|c|c|c|c|c|}
\hline \multicolumn{2}{|c|}{ Rail pads } & $\begin{array}{c}\text { Secant } \\
\text { stiffness } \\
(\mathrm{kN} / \mathrm{mm})\end{array}$ & $\begin{array}{c}\text { Mean } \\
\text { value } \\
(\mathrm{kN} / \mathrm{mm})\end{array}$ & $\begin{array}{c}\text { Variation } \\
\text { coefficient } \\
(\%)\end{array}$ \\
\hline \multirow{3}{*}{$\begin{array}{l}\text { CR rail } \\
\text { pads }\end{array}$} & Sample 1 & 8705.88 & \multirow{3}{*}{8036.00} & \multirow{3}{*}{22.01} \\
\hline & Sample 2 & 6029.94 & & \\
\hline & Sample 3 & 9372.19 & & \\
\hline \multirow{3}{*}{$\begin{array}{l}\text { DT rail } \\
\text { pads }\end{array}$} & Sample 1 & 1876.24 & \multirow{3}{*}{1959.45} & \multirow{3}{*}{19.99} \\
\hline & Sample 2 & 2386.24 & & \\
\hline & Sample 3 & 1615.86 & & \\
\hline
\end{tabular}

For a more detailed study of the dynamic performance of these materials, Figure 5 shows the load-displacement curve measured in cycle 1000 of the dynamic test for sample 1 of the CR rail pads and DT rail pads. As can be observed, in the same way as in the static test 


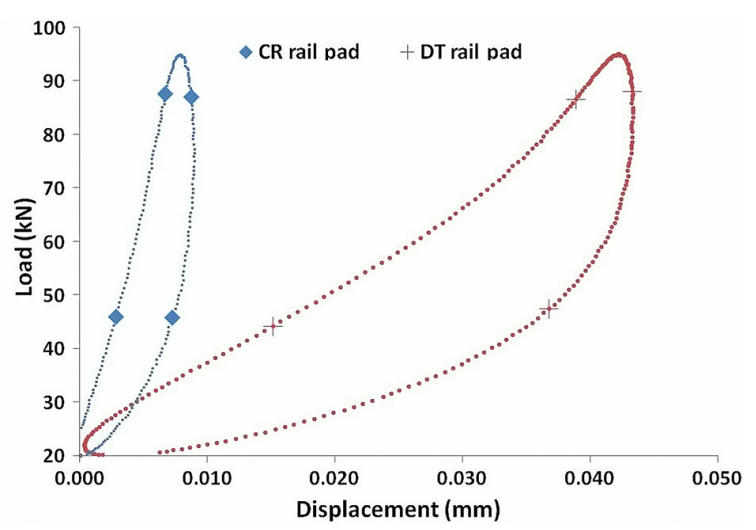

Fig. 5. Load-displacement curve of the dynamic test

for loads of $20-95 \mathrm{kN}$, the crumb rubber rail pad had lower vertical displacement values, which is indicative of greater stiffness when subjected to repeated loads. In contrast, the DT rail pad allows greater deflections, thus guaranteeing a more effective damping of the vertical loads caused by the passage of trains (Fonseca Teixeira 2003; López Pita 2006). Furthermore, the displacement values measured during the static test showed that the dynamic application of vertical loads reduced the deformations in both types of rail pad. This reflects the stiffening of these materials under the dynamic loads to which they will be subjected during their service life.

In regards to the dynamic performance of the rail pads, Figure 6 shows the change in dynamic stiffness (DS) and dissipated energy (DE) for the loading cycles of sample 1 of DT and CR rail pads. The results show that when the number of loading cycles increased, the stiffness of the CR rail pad also increased, a tendency that persisted until the end of the test (1000 loading cycles of 20-95 kN). However, the DT rail pad, after a slight increase in stiffness during the first 600 cycles, maintained a constant dynamic stiffness value of about $1700 \mathrm{kN} /$ $\mathrm{mm}$. This means that after the mechanical conditioning of the DT rail pad, its dynamic performance stabilized, thus assuring an effective response to the repeated loads that occur on railroad tracks. Insofar as its energy per-

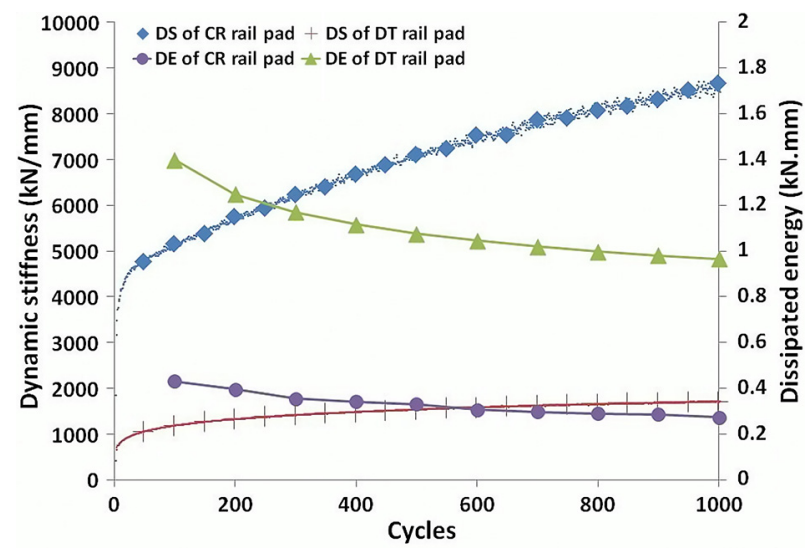

Fig. 6. Dynamic stiffness (DS) and dissipated energy (DE) for DT and CR rail pads formance, the DT rail pad dissipated more energy than the $\mathrm{CR}$ rail pad, probably because of the difference in stiffness values. Consequently, the $\mathrm{CR}$ rail pad was found to have a lower capacity to dissipate the loads transmitted by trains, which can accelerate the deterioration of sleepers and ballast.

\subsection{Fatigue strength}

Figure 7 shows the evolution of the dynamic stiffness (DS) and the accumulated dissipated energy (ADE) of sample 1 of the DT and CR rail pads. The ADE was obtained as a sum of the dissipated energy by the materials in each load cycle, which is measured by the area locked up inside the recorded hysteresis cycles. Thus, the ADE allows analyzing the capacity of the rail pads to damp loads during their service life.

The results show that the dynamic stiffness of the DT rail pad remained constant at the different load levels though it slightly increased when the load changed from a lower level to a higher one. In contrast, the CR rail pad experienced severe stiffening when the load cycles increased in number as well as amplitude. This signifies that it has a lower long-term capacity to damp repeated loads as well as more severe ones. This stems from the deterioration in the mechanical performance of this type of pad during the fatigue test. Furthermore, based on the ADE results for both types of rail pad, it was found that the DT rail pads dissipated more energy when subjected to repeated loads. In fact, this tendency even accentuated as the number of cycles increased. This indicates that during the service life of these materials, the DT rail pad is capable of reducing the energy transmitted to the sleepers and the granular layers of the railroad track. Since there is less deterioration, this has the advantage of also reducing maintenance work (especially in the ballast layer) as well as the cost of this work.

Figure 8 shows the long-term evolution of the permanent displacement obtained for sample 1 of the DT and $\mathrm{CR}$ rail pads during the dynamic mechanical fatigue test. As can be observed, the CR rail pad experienced a significant increase in residual displacement during the

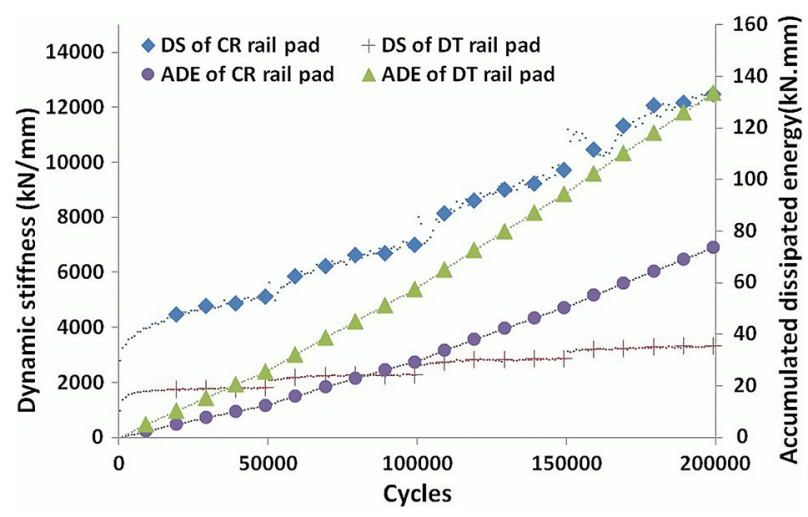

Fig. 7. Long-term analysis of dynamic stiffness (DS) and accumulated dissipated energy (ADE) 
repeated application of the loads. The deformation was even more evident as the load levels became greater. In contrast, even though the DT rail pad initially showed higher values of residual deformation than the CR rail pad at the first load level, it showed a constant elastic performance because its minimum displacement remained almost invariable as the load cycles and amplitude increased. Consequently, the DT rail pad had a better elastic recovery after the fatigue tests of the material and also showed a better long-term mechanical response to the application of loads simulating the passage of trains.

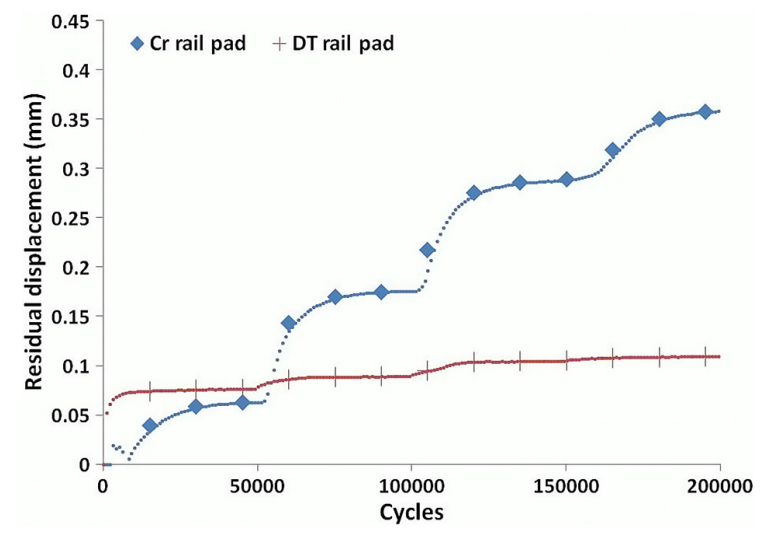

Fig. 8. Evolution of the residual displacement of the DT and $\mathrm{CR}$ rail pad

In order to complete the durability test of both materials in response to the application of dynamic loads, a static test was performed with loads of $20 \mathrm{kN}-95$ $\mathrm{kN}$ for the samples subjected to the fatigue test. It was found that the stiffness of the crumb rubber rail pad increased from $287.86 \mathrm{kN} / \mathrm{mm}$ to $341.95 \mathrm{kN} / \mathrm{mm}$ (18.79\%) whereas that of the deconstructed tire rail pad increased from $290.84 \mathrm{kN} / \mathrm{mm}$ to $325.87 \mathrm{kN} / \mathrm{mm}(12.05 \%)$. This signified that both types of rail pad are apt to be used in railroad tracks though the DT rail pad experienced less elastic deterioration.

\subsection{Effect of climate conditions}

DT and CR rail pads then underwent freeze-thaw and thermal ageing processes to study the change in their static and dynamic performance. Table 4 shows the variation in static stiffness (SS) and dissipated energy (DE) measured in the last load cycle of the $20-95 \mathrm{kN}$ static test in reference to the results obtained for these materials before the artificial deterioration process. Moreover, the table also provides the change in dynamic stiffness (DS) and accumulated dissipated energy (ADE) obtained in the dynamic test for both types of rail pad as compared to the results before the deterioration process.

The results of these tests showed that the static and dynamic stiffness of the rail pads increased when they were subjected to both artificial deterioration processes. However, it was also observed that in the case of the $\mathrm{CR}$ rail pads, their substantial increase in stiffness was
Table 4. Variation in the static and dynamic performance of the rail pads after freeze-thaw and thermal ageing processes.

\begin{tabular}{lcccc}
\hline \multirow{2}{*}{ Rail pads } & \multicolumn{2}{c}{ Variation (\%) } & \multicolumn{2}{c}{ Variation (\%) } \\
\cline { 2 - 5 } & SS & DE & DS & ADE \\
\hline \multicolumn{5}{c}{ Freeze-thaw } \\
\hline CR rail pad & 40.74 & -11.87 & 2.44 & -22.65 \\
\hline DT rail pad & 11.39 & -8.52 & 8.34 & -8.28 \\
\hline \multicolumn{5}{c}{ Thermal ageing } \\
\hline CR rail pad & 158.41 & -71.30 & 53.85 & -7.53 \\
\hline DT rail pad & 5.08 & -9.77 & 10.69 & -3.30 \\
\hline
\end{tabular}

accompanied by a reduction in capacity to dissipate the energy generated by the passage of trains. This occurs because of the severe deterioration of the properties of the resin binding agent. This tendency is even more significant in the static performance of CR rail pads after the thermal ageing process. The results show an increase in stiffness of $158.41 \%$ and a decrease in dissipated energy of $71.30 \%$, as compared to the values obtained before the ageing process.

In contrast, the DT rail pads performed much better. Both deterioration processes had a similar effect on their static and dynamic behavior. The rail pad slightly increased in stiffness $(11.39 \%)$ and experienced an even slighter reduction in its capacity to dissipate energy $(9.77 \%)$. These results show that the DT rail pads have greater deterioration strength than the CR rail pads. They also show that the capacity of these DT rail pads to damp and dissipate the loads transmitted to the rest of the railroad track remains virtually unchanged during their service life.

\section{Conclusions}

This research study analyzed the viability of using EOL tires as elastic pads in railroad tracks. The first set of pads was designed by deconstructing EOL tires by removing the outer tire layer without the need to apply any type of mechanical processing that could modify its the properties. This research analyzed the mechanical response of a set of deconstructed tire (DT) rail pads to compression loads that simulated railway loads in a static and dynamic state. The long-term dynamic response of the material was also analyzed. The results were compared with those obtained for a second set of commercial crumb rubber (CR) rail pads, which was used as a reference value. Furthermore, the environmental ageing of both DT and CR rail pads was studied by subjecting them to freeze-thaw cycles and a thermal ageing process to analyze the static and dynamic performance of these materials. From the results obtained in the tests, it was possible to derive the following conclusions:

- For loads of 20-95 kN, DT rail pads were found to have static stiffness values that were similar to those of the commercial CR rail pads. The results for both types of pad showed low variability. 
- Moreover, the DT rail pads had higher vertical deformation values as well as elastic recovery values. This indicates that the use of these pads in the railway system could contribute to a greater damping of the loads and vibrations transmitted by rolling trains.

- The maximum vertical displacement values for DT and $\mathrm{CR}$ rail pads are very similar for compression loads $(200 \mathrm{kN})$, which are greater than normal in railway systems, even though the DT rail pads obtained higher secant stiffness values $(100-200 \mathrm{kN})$. This is because the material stiffens when the compression loads increase, which is typical of rubber rail pads.

- In a dynamic state, the stiffness of DT and CR rail pads increased in comparison to the results of the static tests though the increase was greater in the case of commercial $\mathrm{CR}$ rail pads. Consequently, the DT rail pads showed a greater capacity to damp dynamic loads.

- Furthermore, the increase in dynamic stiffness during the fatigue test was lower for the DT rail pad. This signified that this rail pad was less affected by the increase in the number of loading cycles as well in the load amplitude. This showed that the DT rail pads experienced less deterioration in regards to their mechanical properties than the commercial CR rail pads.

- The DT rail pads showed a greater capacity to dissipate the energy from the loads generated by the passage of trains. In this way it was possible to reduce the energy transmitted to the sleepers and ballast, and thus mitigate the deterioration of these railway components.

- The environmental ageing of the DT rail pads was found to be lower than that of the commercial CR pads.

The results of this research study prove the viability of using rail pads made from deconstructed tires on railway tracks. This material gives the pads more elasticity and greater damping capacity of the loads and vibrations caused by the passage of trains. Moreover, by using EOL tires for this purpose, it is possible to reduce the accumulation of a waste that would otherwise be difficult to eliminate. This is an important contribution to efficient and sustainable development.

\section{Acknowledgements}

This research was funded by the Spanish Ministry of Science and Innovation and was carried out within the framework of the I+D project, Diseño y Puesta en Valor de Paneles Anti-vibración Fabricados con Material Secundario Procedente de Neumáticos Usados para su Aplicación en el Campo de las Infraestructuras Ferroviarias [Design and Valorization of Anti-Vibration Pads Manufactured with Material obtained from End-of-Life Tires for their Use in Railway Systems] (ref. IPT-20111963-310000).

\section{References}

ADIF. 2013. E.T. 03.360.574.2 Suelas bajo traviesa para alta velocidad [online]. Administrador de Infraestructuras Ferroviarias [cited 27 May 2013]. Available from Internet: www.adif.es

Carrascal, I. A.; Casado, J. A.; Polanco, J. A.; Gutiérrez-Solana, F. 2007. Dynamic behaviour of railway fastening setting pads, Engineering Failure Analysis 14(2): 364-373. http://dx.doi.org/10.1016/j.engfailanal.2006.02.003

CDM [online]. 2013 [cited 29 April 2013]. Available from Internet: http://cdmse.com

Di Mino, G.; Di Liberto, C. M. 2012. Experimental survey on dry asphalt rubber concrete for sub-ballast layers, Journal of Civil Engineering and Architecture 6(12): 1615-1626.

Federation Internationale de la Precontrainte, Commission on Prefabrication.1987. Concrete railway sleepers. FIP State of Art Report. Thomas Telford.

Folta, Z. 2011. Mechanical characteristics testing of the rubber elastic pads under rail. Department of parts and mechanisms of machines, VSB-Technical University of Ostrava.

Fonseca Teixeira, P. 2003. Contribución a la reducción de los costes de mantenimiento de vías de alta velocidad mediante la optimización de su rigidez vertical: $\mathrm{PhD}$ thesis. E.T.S. Ingenieros de Caminos, Canales y Puertos de Barcelona.

Gomavial Solutions [online]. 2013 [cited 25 March 2013]. Available from Internet: www.gomavial.com

Grinys, A.; Sivilevičius, H.; Daukšys, M. 2012. Tyre rubber additive effect on concrete mixture strength, Journal of Civil Engineering and Management 18(3): 393-401. http://dx.doi.org/10.3846/13923730.2012.693536

Hernández-Olivares, F.; Witoszek-Schultz, B.; Alonso-Fernández, M.; Benito-Moro, C. 2009. Rubber-modified hot-mix asphalt pavement by dry process, Journal of Civil Engineering and Management 10(4): 277-288. http://dx.doi.org/10.1080/10298430802169416

Ito, M.; Nagai, K. 2008. Degradation issues of polymer materials used in railway field, Polymer Degradation and Stability 93: 1723-1735.

http://dx.doi.org/10.1016/j.polymdegradstab.2008.07.011

Kaewunruen, S.; Remennikov, A. M. 2008. An experimental evaluation of the attenuation effect of rail pad on flexural behaviour of railway concrete sleeper under severe impact loads. University of Wollongong. Research Online.

Lakuši, S.; Ahac, M.; Haladin, I. 2010. Experimental investigation of railway track with under sleeper pad, in Slovenski kongres o cestah in prometu, 20-22 October 2010, Portorož, Slovenia, 386-393.

Locati, L. 1952. Programmed fatigue test, variable amplitude rotat, Metallurgia Italiana 44(4): 135-144.

López Pita, A. 2006. Infraestructuras ferroviarias. Edicions UPC.

Norambuena-Contreras, J.; Castro-Fresno, D.; Vega-Zamanillo, A.; Celaya, M.; Lombillo-Vozmediano, I. 2010. Dynamic modulus of asphalt mixture by ultrasonic direct test, Journal NDT \& E International 43(7): 629-634. http://dx.doi.org/10.1016/j.ndteint.2010.06.007

Prud'Homme, A. 1977. Solicitaciones de la vía en el intervalo de velocidades de $250 \mathrm{Km} / \mathrm{h}$ a $300 \mathrm{Km} / \mathrm{h}$, y adaptación de la vía clásica a estas velocidades, in Simposio sobre Dinámica Ferroviaria. AIT, 21-58.

Sadkowski, A. 2009. Modelling of the deformation of elastic pads for rail fastenings, Transport Problems 4(1): 63-70.

Sistema MLG [online]. 2013 [cited 29 April 2013]. Available from Internet: www.sistemamlg.es 
Szurgott, P.; Gotowicki, P.; Niezgoda, T. 2012. Numerical analysis of a shaped rail pad under selected static load, Journal of KONES Powertrain and Transport 19(1): 407-414.

UNE-EN 13481-2 Annex B:2003. Requisitos de funcionamiento para los sistemas de sujeción. Sistemas de sujeción para las traviesas de hormigón. AENOR, Asociación Española de Normalización y Certificación, 2011.

UNE-EN 13146-9:2011. Métodos de ensayo de los sistemas de fijación. Determinación de la rigidez. AENOR, Asociación Española de Normalización y Certificación, 2011.
Van Krevelen, D. W. 1990. Properties of polymers: their correlation with chemical structure, their numerical estimation and prediction from additive group contributions. Elsevier, xxii, 875.

Wu, T. X.; Thompson, D. J. 2001. The effects on railway rolling noise of wave reflections in the rail and support stiffening due to the presence of multiple wheels, Applied Acoustics 62: 1249-1266.

http://dx.doi.org/10.1016/S0003-682X(01)00003-2

Miguel SOL-SÁNCHEZ. He is Dr, researcher in the Construction Engineering Laboratory research group at the University of Granada. His research interests include railway materials, asphalt mixes and reuse of wastes in construction.

Fernando MORENO-NAVARRO. Dr, is a Lecturer in the Dept. of Construction Engineering and Engineering Projects and research coordinator of the Construction Engineering Laboratory research group at the University of Granada. His research interests include asphalt mixes, fatigue cracking, reuse of wastes in construction, railway materials, and concrete.

Maria Carmen RUBIO-GÁMEZ. Dr, is a Professor in the Dept. of Construction Engineering and Engineering Projects and Head of the Construction Engineering Laboratory research group at the University of Granada. Her research interests include asphalt mixes, fatigue cracking, reuse of wastes in construction and railway materials. 